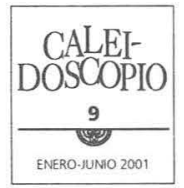

\title{
La hermenéutica analógica-barroca como un modo de abordaje a los procesos educativos
}

ARTURO CRISTÓBAL ĀLVAREZ BALANDRA

Universidad Pedagógica Nacional/Campus Ajusco, México, D.F

La analogía es un híbrido, un mestizo; para muchos, el mestizo es un bastardo. Muchos ven la analogía como un bastardo: ni lo uno ni lo otro; más aún, es más lo otro, la otra cultura; pero lo cierto es que el mestizaje cultural es el único que nos llevará a la comprensión y a la comunicación entre las culturas. Por eso mismo un modelo analógico de la hermenéutica y del diálogo entre las culturas, está por construirse, tendrá mucho que aportarnos.

Mauricio Beuchot

La organización del presente artículo se desarrolla en cuatro momentos: el primero está enfocado a definir qué es la hermenéutica; el segundo explica las implicaciones de la analogía como forma de hacer hermenéutica; el tercero determina cómo se entrelazan la hermenéutica analógica con el ethos barroco, para lograr una nueva síntesis que permita la interpretación de los procesos sociales en América Latina; y el cuarto explica, desde mi punto de vista, cuáles son las posibilidades de aplicación de la hermenéutica analógica-barroca a la interpretación de los procesos educativos del país.

¿QUÉ ES LA HERMENÉUTICA?

Aunque se ha debatido recientemente la derivación de la palabra hermenéutica del dios mestizo Hermes -parte humano y parte divi- 
no-, el cual servía de traductor para llevar los mensajes de los dioses a los hombres, esta derivación tiene, como dice Beuchot: “...el poder de suscitar la idea de que el hermeneuta sirve de intermediario, para lograr una buena comprensión, una buena comunicación..."1

Se puede decir que la hermenéutica surge inicialmente de la Fenomenología ${ }^{2}$ para posteriormente articularse con los planteamientos ontológicos de Gadamer y Ricoeur y con la Teoría Crítica de Habermas y Apel. A nivel general, su propuesta ontoepistemológica se enfoca a establecer las condiciones de construcción de conocimiento de los procesos histórico-sociales en un sentido interpretativo, la cual se da, en contra del univocismo monolítico positivista ${ }^{3}$ que imponía como única forma de pensar y hacer ciencia: la lógica verificacionista basada en la comparación, el control "riguroso" (de laboratorio) de las condiciones de investigación y la supuesta neutralidad que el sujeto teorizante asume en dicho proceso. ${ }^{4}$

1 Beuchot, M. "Hermenéutica (Huir a la herejía)", en Excélsior (Suplemento cultural), año 1, tomo I, núm. 28, domingo 15 de agosto de 1999, p. 3.

2 “...si observamos antecedentes de la hermenéutica nos encontramos con las investigaciones fenomenológicas de Husserl y Heidegger. Claro que la fenomenología no fue en sus orígenes una filosofía del lenguaje, sino una filosofía de la conciencia cuyo objetivo era aclarar la relación sujeto-objeto en el proceso del conocimiento." Cfr. Arriarán, S. "Los aportes de Habermas y Apel al debate sobre hermenéutica y educación", en Revisla Aleph, Colegio de Investigadores en Educación de Oaxaca, año 2, núm. 4, mayo/julio 1998, p. 11.

3 Vid. Velasco, A. "Interpretación, heurística y racionalidad", en Beuchot, Puente, (coord.) La voz del texto, polisemia e interpretación, 1998, p. 213.

4 "Es en las diferentes versiones de la concepción positivista, que en la actualidad se erige como la concepción hegemónica de ciencia y teoría, donde se ha hecho creer que la realidad es asible, cognitivamente hablando, de manera neutral, directa e inmediata por el científico. Son los seguidores de esta concepción, los que presenta al científico como un sujeto que se encuentra más allá de las vicisitudes mundanas". Álvarez, A., Elementos para la crítica epistemológica de la investigación educativa, SEP/UPN-Dirección de Investigación, México, 1998. p. 124.También: Vid. Ibid., pp. 51-59. 
Los teóricos de la hermenéutica la ubican como ciencia y arte a la vez, como ciencia implica un conjunto estructurado de conocimientos que definen su concepción onto-epistemológica y como arte enseña la aplicación correcta de la interpretación a partir de los principios que la condicionan. Así, como ciencia (hermenéutica docens) implica una teoría general de la interpretación, y como arte (hermenéutica utens) proporciona los instrumentos hallados en la teoría general de la interpretación para ser aplicados en la práctica. ${ }^{5}$

En la hermenéutica, la interpretación del texto no es una interpretación unida a otra interpretación sin más, sino la interpretación de la interpretación de un proceso concreto, en la que el intérprete implica su comprensión valoral ${ }^{6}$ para el entendimiento de la intención del autor. Es la búsqueda por captar lo que el autor y el texto dicen por parte del intérprete, en donde: el texto tiene un contenido el cual implica un sentido o intencionalidad ${ }^{7}$ dado por el autor y susceptible de ser comprendido por el lector y una referencia respecto de la realidad en él contenida (pensada o concreta); mientras que el autor, es el emisor del mensaje en el cual implica su intencionalidad; y, el lector, el intérprete del texto que contiene la intencionalidad del autor, pero que además le imprime la propia.

Para ello, el acto hermenéutico necesariamente implica polisemia, pues sólo donde hay múltiples sentidos es posible la generación de múltiples interpretaciones. Donde no es posible la polisemia, donde hay un solo sentido, como en el caso del

5 Vid. Beuchot, M., Tratado de hermenéutica analógica, UNAM, FFL, México, 1997, pp. 15-17.

- Vid. Ortiz-Osés, A., La nueva filosofía hermenéuica, Anthropos, Barcelona, 1986, p. 34.

7 Respecto de la intencionalidad del texto, vid. Eco, U. 1992, Los límiles de la interpretación, Lumen, 1992, p. 29. 
univocismo positivista, ${ }^{8}$ no existe el acto hermenéutico. Es por esto por lo que la hermenéutica está asociada con la sutileza interpretativa en la que se pasa del sentido superficiál al profundo, a la diversidad de éstos cuando parecía haber uno solo, en una búsqueda por desentrañar el sentido auténtico dado por el autor; pues como dice Beuchot:

[En la hermenéutica...] se trata de captar lo que el autor quiso decir. Es la intención del autor o la intención del texto frente a la mera intención del lector, pues en la interpretación convergen tres cosas: el texto (con el significado que encierra y vehicula), el autor y el lector. Y el lector o intérprete tiene que descifrar el contenido significativo que el autor dio a su texto, sin renunciar a darle también él algún significado o matiz. La hermenéutica, pues, en cierta manera, descontextualiza para recontextualizar, llega a la contextuación después de una labor elucidatoria y hasta analítica. [Porque...] la verdad del texto comprende el significado o la verdad del autor y el significado o la verdad del lector, y vive en su dialéctica.?

Así, el corpus del conocimiento hermenéutico es moldeado por el acto de interpretación en un sentido dialógico que no se limita al objeto en sí mismo, sino que implica proporción entre la intuición y el discurso, entre la compresión y el argumento probatorio, entre la innovación y la justificación de la misma. La hermenéutica es la interpretación-comprensión de la relación relatada en y por el lenguaje, por el texto (hablado, escrito, actuado) al ponerlo en su contexto y aplicarlo al contexto actual; $i$. e., sin contextuar la interpretación hermenéutica no es posible, pues la comprensión-interpretación de procesos sociales concretos es el

8 Dice Velasco: "En la filosofía de la ciencia positiva la comprensión (verstehen) como proceso de interpretación de significados, ha sido considerada tradicionalmente como un proceso mental o psicológico que no conduce a un auténtico conocimiento. En el mejor de los casos es considerado como un mero auxiliar heurístico para la formulación de hipótesis". Velasco, A., op. cil. p. 207.

9 Beuchot, M. op. cil., pp. 12 y 21. 
resultado inmediato y casi simultáneo de la contextuación. ${ }^{10}$ Porque la hermenéutica, como dice Gadamer:

...se hace abogada del sentido común en tanto en cuanto que remite a la razón logos como instancia auténtica de nuestras decisiones prácticas, incluso cuando no se reflexiona más por creer que otros -como, por ejemplo, la ciencia- lo abrían hecho por uno mismo. Pienso que es sobremanera falso pensar que pudiéramos existir simplemente sin la función crítica de la ciencia frente a nuestros prejuicios, pero pienso que es tan falso asimismo pensar que podemos existir sin la función crítica de la razón hermenéutica frente a la ciencia. ${ }^{11}$

Para ello, el quehacer hermenéutico no ha sido pensado y realizado de una sola forma, ya que en su larga historia (los griegos, el medievo, el renacimiento, la modernidad y ahora la posmodernidad), su hacer, hasta en un mismo momento, ha implicado diferencias en la ontología, epistemología y metodología que le sirven de sustento teórico y de su praxis; e. g., podemos hablar de: la hermenéutica filosófica de Gadamer, la hermenéutica metafórica de Paul Ricoeur, la hermenéutica crítica de Habermas, la hermenéutica analógica-barroca de Beuchot y Arriarán.

Para esto es necesario explicar, de manera muy general: ¿qué implica la analogía como forma de hacer hermenéutica?

En el lenguaje común se usa el concepto de la analogía como la explicación que se extiende de un caso a otro, por razones de semejanza. En cambio, en el ámbito de la filosofía se debe entender a la analogía como la categoría lógica ${ }^{12}$ que permite ordenar

10 Vid., Beuchot, M., Perfiles esenciales de la hermenéutica, UNAM, IIF, México, 1997, p. 9.

11 Gadamer, H.-G., "Hermenéutica", en Ortiz Osés, A. y Lanceros, Patxi, Diccionario de hermenéutica, Universidad de Deusto, España, 1998, (Ser, Filosofía; 26), p. 229.

12 “...epistemológicamente hablando [...] las categorías deben ser pensadas como el herramental cognitivo que históricamente surge y a partir del cual 
las cosas en una jerarquía según la relación de proporción que guardan entre sí, considerando la diferencia sin abandonar la unidad. Así, Raúl Alcalá plantea que para Beuchot "...la analogía se constituye por tres elementos, un nombre que es común a varias cosas, y tal nombre da significado a una razón o concepto, estableciendo así las relaciones entre las cosas analogadas y esa razón significada..."13

Para ello, la analogía no es de un solo tipo, sino que puede ser clasificada en tres clases diferentes.

La primera que refiere a la desigualdad, pues en ella las cosas participan de un nombre en común, pero no de la misma manera. Esta participación, depende del grado de perfección del objeto analogado, siendo esta analogía impropia, porque la prioridad y la posterioridad en una noción o en una razón en el fondo son la misma para los analogados. E. g., el "cuerpo" que refiere a lo múltiple con una misma cosa la cual puede ser dividido en superiores e inferiores lo que hace que no todo lo analogado participa de la misma manera, pues los superiores tienen mayor perfección en relación con los inferiores. Esto implica que la analogía de desigualdad es la más impropia de las analogías, por tener un sentido más bien univocista generalizador.

El segundo tipo, el de la analogía de atribución, es en el que sí se cumple con la prioridad y posterioridad de orden en relación con el significado, pues aunque el nombre es común, la razón significada por él es un término de relación en el que los significados son diversos y guardan una jerarquía. E. g. el del predicado "sano", en el que la razón significada es la sanidad, obtenien-

el investigador hace para sí, para su pensamiento, los contenidos de una realidad deviniente y cambiante". Álvarez, A. "El herramental cognitivo/ opcrativo en los procesos de teorización", en Covarrubias, Francisco (coord.), Los procesos de teorización, CIEO/DEPI, Oaxaca, 1999, p.124.

13 Alcalá, R., Hermenéutica, analogía y significado, Surge, México, 1999, (Colección Magnum Bonum), p. 27. 
do con ella la jerarquía de los demás significados referidos; así, "sano" se aplica de manera principal al individuo que es el sujeto de la sanidad; pero también se aplica de manera secundaria a la medicina, que es su causa eficiente; y por analogía a la orina, que pasa a ser su efecto o signo. ${ }^{14}$

En el caso del tercer tipo de analogía, la de proporcionalidad, se da una semejanza de las relaciones más que de los conceptos. Para ello, este tipo de analogía se subdivide en analogía de proporcionalidad propia y analogía de proporcionalidad impropia o metafórica. En el primer caso, el de la analogía de proporcionalidad propia, es el de la analogía más perfecta, pues el nombre común es compartido por ambos analogados manteniendo proporcionalmente las diferencias; e. g., "el corazón lo es al ser humano lo que el cimiento es a la casa", manteniéndose la unidad pero con predominio de la diferencia. En el segundo caso, la analogía de proporcionalidad impropia o metafórica, sólo uno de los términos relacionados recibe la predicación de manera literal y el otro de manera metafórica; e. g., "la risa es al hombre lo que las flores son al prado", con lo que podemos decir, metafóricamente, que "el prado ríe", siendo este tipo de analogía el que más se aproxima a la equivocidad.

Esta diferencialidad prototípica y de grados de complejidad en la analogía permite ubicar las distintas formas de su hacer, sin que para ello se pierda como idea general, el que la analogía es un instrumento lógico que se inclina por la lógica informal que por la formal; plantea Beuchot: “... aun cuando los términos analógicos no invalidan el silogismo -como decía ya Aristóteles-, porque no introduce en ellos ambigüedad completa, lo cual sí lo invalidaría, sino ambigüeùad controlable, la analogía requiere del diálogo para establecerse..."15

14 Vid. Ibid. p. 28; y también, Beuchot, M., op. cil., pp. 30-31.

15 Beuchot, M. "Respuesta", en Alcalá, R., op. cil., p. 42. 
Es así que recuperando estos planteamientos de la analogía para pensar el acto hermenéutico, nos lleva a reflexionar sobre un conjunto de supuestos y conocimientos sintetizados con base en los cuales se define la manera de pensar los procesos cognitivos aplicados al acto interpretativo. Así, en la hermenéutica analógica se acepta todo tipo de analogía, ${ }^{16}$ con la pertinencia de que en ella, la construcción de conocimiento de los procesos sociales debe mantener un punto de equilibrio entre las semejanzas y las diferencias que son las que predominan, una posibilidad de conmensurabilidad que no impida reconocer ni niegue la diferencia; porque, como dice Beuchot: "De esta manera no se exigirá una única interpretación como posible o válida, ni tampoco se dejará abierto hasta el infinito el ámbito de las interpretaciones a la vez posibles y válidas...". ${ }^{17}$

Para ello, es necesario que el sujeto del acto hermenéutico cuente con el instrumental que le permita acceder a la interpretación profunda. Una interpretación que no se limita a la cotidianidad inmediatista de carácter puramente práctico utilitario; sino que implica, además, poner en práctica una serie de referentes pertinentes para develar las formas y contenidos a través de los cuales se expresa el texto, su contexto y la intencionalidad del intérprete.

16. Raúl Alcalá critica a Mauricio Beuchot el hecho de que no define qué tipo de analogía es la que él asume en su hermenéutica analógica. Vid. Ibid. p. 28. A esto Beuchot contesta: "En mi construcción de la hermenéutica analógica acepto todos los tipos de analogía. Precisamente lo que hago es radicalizar la hermenéutica en el sitio que la dejó Paul Ricoeur. El privilegió la metáfora como modelo de la tensión dialéctica que se da en la verdad textual. Yo creo que se puede ampliar el modelo hermenéutico de modo que abarque no sólo la metáfora, sino también la de desigualdad, la de atribución y la de proporcionalidad propia". Ibidem, p. 43. Aquí mismo indica que si tuviera que elegir entre los tipos de analogía optaría por la de proporcionaliclad propia porque está sujeta y de alguna manera guía a la metáfora y amplia las posibilidades de verificación argumentativa.

17 Beuchot, M., Tratado de hermenéutica analógica, p.9. 
Para ello, los principios básicos que orientan el acto interpretativo de la hermenéutica analógica son: a) la dialogicidad en el acto interpretativo que sólo es posible cuando hay polisemia; b) el vínculo teoría-praxis que implica el reflexionar para realizar práctica en procesos concretos; c) el relativismo relativo con sus límites, porque hay una comunidad o universalidad restringida y una diversidad o particularidad extendida; $d$ ) la finitud-infinitud, pues a pesar de que la mente del hombre es finita, la potencialidad de los conocimientos e interpretaciones por ella generada implican una infinitud; e) la espiralidad del acto interpretativo, en el que el conocimiento no es un círculo cerrado, sino una espiral del cambio; ${ }^{18}$ f) la creatividad, que es la única y misma vía de la interpretación; g) la ontología como fundamento del conocer y de lo conocido; $h$ ) el equilibrio que es dinámico, pues mantiene un estado de tensión entre la diferencia y la unidad; i) el límite, que permite que la diferencia-unidad se entretoque y entrecruce sin perderse, sin confundirse y sin desaparecer, pero manteniendo un estado de tensión dinámica; y, $j$ ) la explicación-innovación como fin último del acto interpretativo, el cual no rompe con la tradición sino le aporta algo y lo adecua al presente (un cambio analógico ni totalmente sustancial ni meramente accidental).

Con base en estos supuestos, ahora se puede preguntar: ¿cómo es que se entrelaza la hermenéutica analógica con el ethos barroco para lograr una nueva síntesis que permite realizar el acto interpretativo de los procesos sociales en América Latina y en especial en México?

Plantea Beuchot que en el acto interpretativo se entremezcla la intencionalidad del autor con la del intérprete, la cual debe mantener un equilibrio que permita llegar a una mediación prudencial y analógica en la que la intención del autor se respete, pero con la advertencia de que la intencionalidad del lector estará presente. Vid. Beuchot, M., op. cil. pp. 2021 y Perfiles esenciales de la hermenéutica, pp. 45-48. 
Los orígenes del ethos barroco ${ }^{19}$ se ubican en Europa, sin que esto signifique que se halla expresado de la misma manera en todos los lugares donde se dio. En el caso del norte de Europa el barroco se ubica en el terreno del arte, la pintura y la arquitectura; en cambio, en el sur de este mismo continente, además del arte, la pintura y la arquitectura, se extiende como proyecto político específico para la Contrareforma modernizadora cultural. Esta reforma, dice Kurnitzky:

No es solamente -sobre todo en el caso de los jesuitas-un intento de "parar el golpe" que han recibido por parte de los reformadores, sino de devolver un golpe más fuerte, es decir, de ir más allá del protestantismo. La idea de los jesuitas es la de hacer de la experiencia mística un fenómeno popular y no reservado a unos cuantos, es decir, pretenden una auténtica secularización de la mística para hacer que la gente viva todo el tiempo en el límite, en el borde entre lo terrenal y lo celestial. ${ }^{20}$

Los jesuitas son los que proyectan esto, al introducir una planeación de la fe, para lo cual, ellos convierten el barroco en estilo oficial para organizar la vida social, cultural y económica, todo esto con el propósito de competir con la ética productivista del protestantismo. ${ }^{21}$ Es así, que el barroco tiene una gran influencia en Italia y España, lo que permite su llegada a América Latina, lo cual implica una nueva síntesis con sus peculiaridades, con sus especificidades, pues dice Bolívar Echeverría, refiriendo el mercado como el lugar de excelencia del mestizaje cultural, que:

19 "En el elhos se encuentra una afirmación incondicional de la forma de la forma 'natural' de la vida social; pero en él, por el contrario, tal afirmación tiene lugar dentro del propio sacrificio de esa iorma "natural"; la positividad - el valor de uso- se da a través de la negatividad -la valorización del valor económico-." Kurnitzky, H. y Echeverría, B. Conversaciones sobre lo Barroco, UNAM, México, 1993, p. 69.

Ibid., p. 14.

21 El colapso de la fe católica se da, durante el siglo XVIII, en Europa. 
La diversificación de su sistema de necesidades sería un resultado de la presencia del mercado. El mercado sería en este sentido, potenciador del sistema de necesidades y, al potenciar el sistema de necesidades, implicaría su mezcla o interpretación con otros[...]. Lo que está en juego en el mercado es la interpretación, la mezcla, el mestizaje de las distintas formas. En el caso del mestizaje étnico o en el caso de una situación histórica que gira en torno a la interpretación de esquemas civilizatorios heterogéneos, esta estructura propia del mercado se presenta de manera concreta en la persona del individuo social; el mestizo es el que está condenado [...] a representar el conflicto en sí mismo, a ser el conflictivo viviente de esta utopía del mestizaje de los valores de uso. Porque en el mestizo, en su existencia, estaría viviéndose de esta universalización, de esta conjunción de múltiples figuras del mundo de la vida. ${ }^{22}$

Este proceso, al que alude Bolívar Echeverría y que implica a la misma educación, es lo que aquí nos interesa, ya que es a través del mestizaje, de la mezcla de distintos sistemas de necesidades (culturales, políticas y económicas), lo que caracteriza el barroco en América Latina. Un mestizaje ${ }^{23}$ que no sólo es lo biológico y étnico sino principalmente una forma de cultura, de educación, de economía y de política; en el que los jesuitas proponen la posibilidad de que se dé el tránsito entre lo terrenal y el reino de los cielos como un continuo que en algún momento o punto se tocan y son lo mismo, pero mantiene sus límites. E. g., al pintar un espacio interior, Baciccia lo presenta como un lugar en el cual debe saberse que lo terrenal se está abriendo hacia lo celestial, pero que a la vez se está descendiendo de éste, así lo terrenal implica los límites entre lo normal y lo milagroso; un tanto aplicable a la idea del profesor como apóstol de la educación y al saber $^{24}$ como el reino de los cielos.

22 Kurnitzky, H. y Echeverría, B. op. cil., pp. 20 y 22.

23 La pureza como tal no es natural, pues sólo es una construcción abstracta. En la naturaleza la pureza es algo desconocido, porque la supuesta pureza es una nueva síntesis producto de la diferencia.

24 Ubico el saber como el acto memorístico acumulativo de información y el 
Con el proceso de gestación de una sociedad cada vez "más moderna", el barroco en América Latina se consolida como una forma de organización social que se da manteniendo ciertas fronteras, pero que además implica un cuadro del conflicto en el que se intenta, al mismo tiempo, encerrarlo dentro de ciertos parámetros que a la vez permiten desatarlo al máximo dentro de ellos mismos; un ethos barroco que se privilegia e impone como modo de vida. ${ }^{25}$

Así, en el caso específico del mundo capitalista moderno de América Latina, el ethos barroco ${ }^{26}$ implica una identidad que oscilá permanentemente entre dos lógicas contradictorias entre sí: por un lado, la forma concreta o "natural" del proceso de producción-consumo de la riqueza social que debe ser globalizada o mundializada y por el otro, la valorización de las tradiciones culturales y el reconocimiento a la diversidad que caracteriza a cada una de las naciones. Un barroco de vacilación entre los bordes, entre el ser quien expresa y el ser la expresión, entre el ser puesto o constituido y el ser quien pone y constituye. Una búsqueda por hacer de la educación una estrategia para la igualdad y por el otro, un mecanismo de respeto para la diversidad cultural.

El ethos barroco en América Latina es otra manera de ser, una fusión de dos culturas de manera tal que las dos coexisten en una tercera que es su síntesis, que por el momento histórico-social

conocimiento como comprensión de la lógica de construcción y de integración de los saberes.

Vid. Ibid., pp. 61-64.

26 "Con el advenimiento de la modernidad hay cuatro posibles formas de respuesta de los individuos a este hecho: la realista, la romántica, la clásica, y la barroca. La respuesta de tipo barroco o elhos barroco tendría su escenario privilegiado en América Latina." Ibid., p. 61. 
en que nos encontramos, implica una intención política en la que se entrelaza la cultura moderna con la cultura indígena. ${ }^{27}$

Así, la filosofía del barroco implica pensar en otra forma de racionalidad en contra del espíritu serio, neopositivista, analítico y neoliberal, en el que, como dice Arriarán: “...se trata de rescatar esta racionalidad hermenéutica analógica, [...]como una filosofía del juego, de la imaginación creadora y de la libertad." ${ }^{28}$ Un barroco del mestizaje y del multiculturalismo analógico que busca la igualdad proporcional con predominio de la diferencia, la cual debe ser respetada, para no caer en un pesimismo histórico que niegue la reflexión política que pone en evidencia el fracaso de la modernidad $^{29}$ globalizadora eurocentrista. Un barroco que es terreno fértil para la analogía que conceptúa al tiempo como una cualidad de lo real, $i$. e., como cualidad de la interpretación del momento histórico en el que una sociedad específica es y existe; pues como dice Paul Ricoeur:

...el tiempo se hace humano en cuanto se articula de modo narrativo; a su vez, la narración es significativa en la medida en que describe los rasgos de la experiencia. [Así pues...] lo que se plantea, se dice y se piensa es, al mismo tiempo, el contraste de la eternidad y del tiempo. El trabajo de la inteligencia no se refiere en absoluto a la cuestión de saber si la eternidad existe. La anterioridad de la eternidad respecto del tiempo - en un sentido de anterioridad que queda todavía por determinar- se da en el contraste

27 Dice Arriarán: "El barroco del que hablamos [es...] otro barroco, no el del pesimismo histórico, sino el de la esperanza y la renovación cultural". Arriarán, S. y Beuchot, M., Filosofía, neobarroco y mulliculturalismo, Itaca, México, 1999, p. 12.

28 Ibid., pp. 11 y 12.

29 Dice Constante: "Cinco son los fenómenos en que se resume la fisonomía espiritual de la Época Moderna y que, a la base de ellos está la metafísica: La ciencia, la técnica, el arte como estética, la actividad humana como cultura y la desdivinización o desacralización" Constante, A. "La crisis de la modernidad y del humanismo". En: Yáñez, A. (coord.), Diálogos sobre onlología y estélica, UNAM/AFM, México, 1996, p. 68. 
entre "todo lo que no ha sido creado y, sin embargo, existe" y el que tiene un antes y un después, que "cambia" y que "varía"..."

Es en este pasado presente-futuro presente, ${ }^{31}$ en donde se dan las condiciones del momento histórico de una sociedad, en la que el barroco muestra cómo la idea de moderación se impone, como prudencia, como respeto a la Otredad, como síntesis que busca los límites sin renunciar a la diferencia. Pues, como plantea Arriarán: “...si se puede rescatar la cultura del barroco entonces podemos intentar desarrollar una hermenéutica analógica en las condiciones actuales". 32

Es pues el ethos barroco una manera de replantear el problema del diálogo en función del mestizaje, del cruce intercultural y de hibridación que caracteriza a Latinoamérica; esto conlleva la necesidad de revisar la historia y el problema de la identidad nacional como identidad simbólica que no es pura. ${ }^{33}$ Pero también es, una manera de pensar la posmodernidad, la del equivocismo total, la de la pérdida de toda identidad, de toda

30. Ricoeur, P. 1995, Tiempo y narración, vol. I, Siglo XXI Editores, México, 1995, pp. 39 y 67. En ese mismo texto indica: "Yo distingo tres incidencias importantes de la meditación de la eternidad sobre la especulación concerniente al tiempo. Su primera función es colocar toda la especulación sobre le tiempo bajo el horizonte de una idea-límite que obliga a pensar a la vez el tiempo y lo otro del tiempo. La segunda es intensificar la experiencia misma de la distentio en el plano existencial. La tercera es exigir a esta misma experiencia que se supere en línea de la eternidad y, por lo tanto, que se jerarquice interiormente en contra de la fascinación por la representación del tiempo rectilíneo". Ibid., p. 66.

31 Todo acto interpretativo lo es del presente aunque refiera hechos o postulados del pasado y todo futuro posible es presente construido en forma de proyecto. Vid., Alvarez, A. Elementos para la crílica epistemológica de la invesigación educativa, p. 168; y Zemelman, H., Problemas antropológicos y utópicos del conocimiento, COLMEX, México, 1996, pp. 20 y 40.

32 Arriarán, S., La fábula de la identidad perdida, Mecanograma. 1998, p. 7.

33 Vid. Idem. 
organización social, sin respeto ni límites para la diferencialidad, la de la educación del y por el libertinaje en la que todo se vale y no existe responsabilidad.

Es con base en este tipo de pensamiento analógico metafórico barroco, que se da entre el sentido literal y el sentido simbólicoalegórico, ${ }^{34}$ lo que permite realizar el proceso de comprensión o simbolización de la identidad de la diferencia, que no es abstracta, sino concreta, pues implica una geografía y una historia. Es una hermenéutica no occidental, contemporánea, que recupera lo místico, la tradición del ethos barroco y la analogía como herramental. Una hermenéutica en la que se implica universalización por el mestizaje, para reconocer la individualidad pero en el seno del bien común; pues busca colocarse en los límites del respeto, de la tolerancia, de la discreción proporcional analógica. Como dice Fuentes Herrera:

En el barroco se van a pretender nuevas ordenaciones en las cuales la razón quiere procurar o colaborar activamente en su propia salvación. Ahora bien, para darse la salvación hay que señalar límites, configurar fronteras o situaciones que definan el tránsito de una situación, de un estado anterior primero menesteroso, corrompido o indigente, en términos teológicos de pecado o estado de naturaleza, del cual mediante la acción de la propia razón se pase o se llegue a la salvación, o se entre en el reino de gracia, o se pueda decir que estamos en el reino de gracia. ${ }^{35}$

Es esta nueva síntesis filosófica de la hermenéutica analógicabarroca, la que nos permite interpretar y realizar la praxis para la transformación pertinente de la diferencialidad y diversidad que

34 Dice Beuchot: "La alegoría ha sido definida como una metáfora continua. Pero también es lo que se opone al sentido literal." Beuchot, M. "Emblemas, símbolos y analogicidad-iconicidad”. En: Arriarán, S. y Beuchot, M., op. cit., p. 42.

35 Fuentes H., J. "Spinoza: una filosofía barroca". Apud. Beuchot, M., "Filosofía barroca". En: Arriarán, S. y Beuchot, M., op. cil., p. 33. 
caracteriza a América Latina, a México y a sus distintas formas de expresión educativa y social.

Finalmente, para dar sentido a lo antes dicho sobre lo que es la educación, propondré un conjunto de ideas que permitan, por un lado, entender el uso instrumental que se puede hacer de la hermenéutica analógica para realizar el acto interpretativo de los procesos educativos; y por el otro, ubicar, al igual que Beuchot lo hace, ${ }^{36}$ el ethos barroco de América Latina y, en particular, de México, como un tipo de pensamiento analógico que permite reconocer, repensar y reorientar el multiculturalismo que lo caracteriza y que se sintetiza en la educación. ${ }^{37}$

Para ello, lo primero que hay que comprender en lo planteado hasta aquí, es que la hermenéutica analógica aporta al intérprete de los procesos educativos, el andamiaje categorial y los conceptos de base $\mathrm{e}^{38}$ con los cuales puede realizar el acto hermenéutico. En la hermenéutica barroca se explica y propone la comprensión del mestizaje en México y en América I ptina, no como una identidad abstracta y unitaria ajena a sujetos de carne y hueso que tiene un antecedente peculiar y una territorialidad específica, sino como dice Arriarán: “...una identidad que permite la sustracción de lo sagrado y da lugar a una diferenciación de situaciones geográficas e históricas...". ${ }^{39}$ Es decir, la hermenéutica barroca es una hermenéutica no occidental que postula un antiuniversalismo de crisis cultural e ideológica que se da en una racionalidad mestiza, la cual debe ser tomada en cuenta al proponer políticas de educación y procesos concretos de aplicación de éstas, en un acto de interpretación del texto en su contexto.

\footnotetext{
36 Ibid., p. 25.

37 Arriarán, S. "Introducción". En: Ibid., p. 20.

38 Respecto de la definición de las categorías y los conceptos. Vid., Álvarez, A. "El herramental cognitivo/operativo en los procesos de teorización", pp. $131-132$.

3) Arriarán, S. "Introducción", op. cil., p. 86.
} 
Pero además, en los límites de estas dos dimensiones de la hermenéutica analógica-barroca, la instrumental y la objetual, se deriva una dimensión metodológica, la cual se orienta a la organización y utilización de estrategias cualitativas de investigación (la historia de vida, historia oral, etnografía, investigación-acción, entre otras), no sólo para el acopio de información, sino también para la realización de un acto hermenéutico enriquecido, que permita repensar la realidad social y educativa y que posibilite su potenciación direccional analogada. Así, este plano referencial abstracto de la hermenéutica debe ser concretado a través de la reflexión y de la práctica investigadora, pues sólo en la realización de ésta, como mediación cognitiva, se hace posible lograr el tránsito del acto interpretativo a la praxis.

Concretando lo hasta aquí dicho y para ejemplificar el uso del instrumental de esta nueva síntesis que es la hermenéutica analógica-barroca, se pueden hacer planteamientos como los siguientes. Cuando en la hermenéutica analógica se dice que el acto interpretativo implica dialogicidad, debemos de pensar que la organización de los procesos educativos (políticas educativas, curricula, programas de estudio, sistemas de enseñanza aprendizaje, criterios de evaluación, recursos didácticos, infraestructura, etcétera) debe ser producto del intercambio de ideas de los partícipes para reconocer su diferencialidad manteniendo la unidad de un proceso educativo heterogéneo. E. g. para que la huelga de la UnAm pudiera ser resuelta en una dimensión analógica, es necesario abrir un espacio de debate que permita el diálogo entre autoridades y estudiantes, no como un proceso de simulación en el que-oigo pero no escucho, propongo pero no acepto lo propuesto, defino pero no puedo decidir-; un espacio polisémico que no sea del todo o nada, sino de la razón compartida con ciertos márgenes de conflicto, que por cierto pudiera ser posible al renunciar Barnés.

Por otro lado, cuando se dice que el pensamiento debe esta- blecer un vínculo entre la teoría y la praxis, nos remite a que la 
reflexión y el entendimiento de un proceso concreto explicado desde su dimensión teórica debe ser incidencial y potenciador direccional de éste. $E$. g., al realizar la reflexión filosófica sobre el ethos barroco, Samuel Arriarán ${ }^{40}$ y Bolívar Echeverría, por señalar algunos autores, permiten pensar las condiciones concretas de constitución de la sociedad mexicana, lo que puede ser traducido en un acto de intervención para la organización de una educación que reconozca y respete la diversidad cultural que coexiste en nuestra sociedad. No para formar sujetos acríticos, idénticos, sin tradiciones, sino para integrar manteniendo, sobre todo, en el caso de las etnias, su identidad, su cosmovisión.

Cuando se plantea que la analogía es un relativismo relativo con sus límites, porque hay una comunidad o universalidad restringida y una diversidad o particularidad extendida, es necesario que en la educación se reconozca esto. E. g., Con la Declaración Mundial sobre Educación para Todos en donde se dice: "El principio rector [...] es que las escuelas deben acoger a todos los niños, independientemente de sus condiciones físicas, intelectuales, sociales, emocionales, lingüísticas y otras..." ," lo que se implica es el reconocimiento de la diversidad que debe tener condiciones de igualdad, sin perderse de vista que entre los educandos integrados hay ciertos límites que los diferencian, pero igualdades que los aproximan y permiten su integración con ciertos límites.

40 Dice Arriarán: "Para que haya diálogo es necesario replantear el proceso educativo como un trabajo que permita el respeto a las diferencias culturales, es decir, desarrollar otro sistema educativo basado ya no en la homologación y la integración a una sola cultura (la cultura urbana, estadounidense, occidental), sino en el pluralismo democrático y de la multiculturalidad". Arriarán, S., "Los aportes de Habermas y Apel al debate sobre hermenéutica y educación", p. 5.

4 UNESCO, Declaración de Salamanca, UNESCO-Conferencia Mundial sobre Necesidades Especiales, Salamanca, 1994, p. 1. 
Cuando se sostiene que la mente del hombre es finita, pero que el potencial de los conocimientos generados por ésta es infinito, a lo que se hace referencia es a la memoria histórica que sintetiza el pensamiento construido por el hombre. E. g., si analizamos la "metáfora de la caverna" de Platón, ${ }^{42}$ en donde plantea que la necesidad de que aquellas personas mejor dotadas deben salir de la caverna para adquirir los conocimientos y después regresar para compartir con los demás lo nuevo conocido, se entiende la aplicabilidad a los procesos educativos que el docente dirige y que implican ese acto de ser el facilitador para los educandos en la adquisición de los conocimientos y no en un puro acto contemplativo. ${ }^{43}$

En el caso de la espiralidad del acto interpretativo, podemos ver cómo los procesos de reflexión no implican una finitud, sino al contrario, un permanente construir y reflexionar para proponer condiciones de organización de los procesos educativos. E. g., primero se hablaba del conductismo, después del cognoscitivismo, posteriormente del constructivismo y ahora de la teoría histórico sociocultural; todo esto se da sin que se anule lo anterior.

La posibilidad de crear nuevas formas inéditas de organizar los procesos educativos implica la creatividad que se da en el acto hermenéutico, la cual es acompañada por la interpretación como único mecanismo para acceder a ella; pues no es posible el

42 Dice de manera textual: "Por cierto que es una tarea de nosotros, los fundadores de este Estado, la de obligar a los hombres de naturaleza mejor dotada a emprender el estudio que hemos dicho antes que era el supremo, contemplar el Bien y llevar a cabo aquel ascenso y, tras haber ascendido y contemplado suficientemente, no permitirles lo que ahora se les permite". Platón, Diálogos; República, Credos, Madrid, 1992, (Biblioteca Clásica; IV), p. 534.

43 Sobre lo aquí planteado vid. Escalera, J. "Dialéctica y educación en el Fedro, la República y las Leyes de Platón”. Ponencia presentada en el XIV Congreso Interamericano de Filosofía y X Congreso Nacional de Filosofía, del 16 al 20 de agosto de 1999. p. 4. 
acto interpretativo sin entendimiento y creación. $E$. g., un profesor de educación primaria al relacionarse con sus alumnos reconoce que el proceso educativo se vincula con el juego, por lo que este acto interpretativo le permite proponer nuevas estrategias de enseñanza, nuevos recursos didácticos y nuevas formas de pensar el acto educativo, potenciando con ello, otro tipo de educación y de relación con los educandos.

La ontología como fundamento del conocer y de lo conocido en los procesos interpretativos necesariamente implica todo lo contenido en el pensamiento del sujeto, i. e., el profesor, al enfrentar la problemática de tener que enseñar algún concepto, involucra sentimientos, experiencias y conocimientos, sin que para ello pueda aislar lo racional de su pensamiento al transmitir el concepto, y sin negar que en este proceso existe un contexto del texto en el que se relaciona con el educando. Aquí es donde se puede entender ese equilibrio que es dinámico, pues mantiene un estado de tensión entre la diferencia y la unidad de los educandos y del concepto que se enseña, sin que se confundan y sin que desaparezcan uno por el otro.

En el caso de la explicación-innovación como fin último del acto interpretativo, el cual no rompe con la tradición sino le aporta algo y lo adecua al presente, está presente la posibilidad de hacer uso de los medios, como eso, como medios y no como fines. No es el uso del Internet el fin de la educación, sino uno de los medios que apoyan el proceso educativo y lo enriquecen.

En el caso del ethos barroco que caracteriza a la sociedad mexicana, la cual como nación debe pugnar por lograr la integración pero manteniendo el equilibrio de manera proporcional, permite pensar una educación que posibilite el desarrollo de la sociedad dentro de un marco de democracia y respeto a la diversidad de identidades, de valores y de formas culturales. Una educación que no se enfoque a la integración cultural anulando y despojando de su identidad a los grupos que la integran como nación. Una educación del diálogo y del respeto a las diferencias 
culturales que no sólo sea urbana, que no se oriente al consumo por el consumo, que no sea clasista, que potencie al máximo las habilidades de los educandos, que no genere sujetos analfabetas funcionales con una conciencia acrítica. Una educación que no se limite a la elaboración de libros de texto en el lenguaje de las diferentes etnias, como si esto fuera una educación que respeta y fortalece su identidad, su cosmovisión como grupos que pertenecen a una misma nación. Una educación que reconozca la diversidad de culturas diferentes en el seno de las sociedades nacionales, no para ser sectaria, ni elitista; sino igualitaria y equitativa.

En sí, lo que se plantea es que debe haber una educación que implique un proyecto moderno que permita la integración de las etnias, de las culturas, sin negar y dejar de reconocer sus especificidades como necesarias a una sociedad que es mestiza; pues como plantea Luis Villoro, la problemática del México actual, es la de poder construir un Estado plurinacional. ${ }^{44}$

La educación en México debe ser un proyecto multicultural, ${ }^{45}$ porque la sociedad que lo integra es diversa; un proyecto de entendimiento, compresión y praxis, en el que haya tolerancia, equidad y respeto a la diversidad. Una educación que permita la unidad sin ser univocista y la diferencia sin caer en equivocismos. Una educación que implique el entendimiento y la praxis analógico-barrocas de la sociedad mexicana y en lo general de toda Latinoamérica.

4 Villoro, L. “¿Crisis del Estado-nación mexicana?”. En Revista: Dialéclica, núm. 27, México, 1995, p. 26.

45 Olivé plantea que: "...un modelo de multiculturalismo debe incluir concepciones sobre las culturas y su diversidad, sus derechos y obligaciones, lo que implica las interacciones culturales, la relación entre los individuos y los grupos y, finalmente, acerca de cómo están imbricados los derechos individuales con los derechos de los grupos". Olivé, León. Muliculluralismo y pluriculıuralismo, Paidós/UNAM/FFL, México, 1999, (Biblioteca Iberoamericana), p. 67. 
